\title{
Proceeding
}

Supplementary Issue: Winter Conferences of Sports Science. Costa Blanca Sports Science Events, 22-23 March 2021. Alicante, Spain.

\section{The program for monitoring students' walking and running according to the system "10,000 steps a day" during the spread of COVID-19}

\author{
ROMAN SERGEEVICH NAGOVITSYN ${ }^{1}$, ALEKSANDER YURIEVICH OSIPOV ${ }^{2,3}$, TATYANA IGOREVNA \\ RATMANSKAYA ${ }^{2}$, DENIS VASILEVICH LOGINOV2,3,4,5, DMITRY SERGEEVICH PRIKHODOV 2,3,4 \\ ${ }^{1}$ Glazov State Pedagogical Institute, Glazov, Russian Federation \\ 2Siberian Federal University, Krasnoyarsk, Russian Federation \\ ${ }^{3}$ Krasnoyarsk State Medical University named after professor V. F. Voyno-Yasenetsky, Krasnoyarsk, Russian \\ Federation \\ ${ }^{4}$ Reshetnev Siberian State University Science and Technology, Krasnoyarsk, Russian Federation \\ ${ }^{5}$ Krasnoyarsk State Pedagogical University named after V. P. Astafyev, Krasnoyarsk, Russian Federation
}

\begin{abstract}
Background: During the spread of COVID-19, the need for scientifically based methodological assistance to students when walking and running was most evident in order to improve optimal body functions and maintain health. The aim of the study was to develop a program for monitoring students' walking and running according to the system "10,000 steps a day" during the spread of COVID-19 and to prove its effectiveness through improving body mass index and improving physical health. Study participants: students regardless of gender $(n=114)$. Interventions: The pedagogical research was carried out for 4 months. During the experiment, the students of the experimental group $(n=71)$ carried out self-monitoring of aerobic physical activity, consisting of walking and running, using the author's program according to the principle of "10,000 steps per day" in daily, weekly and monthly cycles. The study used diagnostics of general physical health, the level of functional readiness to perform loads and body mass index. Main outcome measures. The effectiveness of the implementation of the author's program for monitoring aerobic physical activity of students is statistically significant at $p<.01$ and $p<.05$. The implementation of the author's model of independent walking and running is effective only under the condition of systematic fulfilment of aerobic physical loads. Findings. The obtained research data showed that during the period of the spread of COVID-19, an active lifestyle of students, including daily walking and running, is possible and effective for physical health and the prevention of overweight.

Keywords: Walking; Running; 10,000 steps; Program; Monitoring.
\end{abstract}

Cite this article as:

Nagovitsyn, R.S., Osipov, A.Y., Ratmanskaya, T.I., Loginov, D.V., \& Prikhodov, D.S. (2021). The program for monitoring students' walking and running according to the system "10,000 steps a day" during the spread of COVID-19. Journal of Human Sport and Exercise, 16(3proc), S864-S873. https://doi.org/10.14198/ihse.2021.16.Proc3.03

Corresponding author. Glazov State Pedagogical Institute, Glazov, Russian Federation. http://orcid.org/0000-0003-4471-0875 E-mail: gto18@mail.ru

Abstract submitted to: Winter Conferences of Sports Science. Costa Blanca Sports Science Events, 22-23 March 2021. Alicante, Spain.

JOURNAL OF HUMAN SPORT \& EXERCISE ISSN 1988-5202.

(c) Faculty of Education. University of Alicante.

doi:10.14198/jhse.2021.16.Proc3.03

S864 | 2021| Proc3|VOLUME 16

C 2021 University of Alicante 


\section{INTRODUCTION}

Systematic physical exercise is a key condition for the full functioning of all systems of the human body (Troiano et al., 2012). The rational sequence of performing physical exercises in daily, weekly and monthly cycles ensures the transition of the body's physical reactions into long-term adaptation to physical activity (Lee \& Shiroma, 2014). A positive effect from the realization of physical activity is achieved only when motor activity is combined with the action of the next motorcycle, through the compensation of energy resources (Hamaguchi et al., 2020; Podrigalo et al., 2019). This means that the basis for the implementation of effective physical activity is the systematic effect of the load and the regularity of its repetition (Exel et al., 2019; Nagovitsyn et al., 2019). Violation of the principle of regularity and gradualness in the process of realization of motor actions can not only fail to give the desired health-improving and physically developing effect, but also lead to serious health impairments (Nyenhuis et al., 2020; Pitanga et al., 2020). Individual design of a program for the implementation of physical activity, both anaerobic and aerobic, should provide for the correct selection of exercises, their dosage and intensity (Nagovitsyn et al., 2019; Wennman et al., 2019). Unfortunately, scientists note a significant lack of regular physical activity in a significant part of the adult population (Aksović et al., 2020; Loginov, 2019), including university students (Juwono \& Szabo, 2020; Otaraly et al., 2020). Experts point to the need to create and use new pedagogical technologies and new types of physical activity in the educational process for the formation of a healthy lifestyle and the required level of physical activity in students (Kuzmina et al., 2020; Nagovitsyn, 2014).

In the 2020 coronavirus COVID-19 pandemic, a significant part of the population of the Russian Federation, Europe and the whole world was in self-isolation mode in the spring and summer (Saatchian \& Azimkhani, 2020). In the first half of this year, most of the special sports facilities for active physical education and sports were closed (Chen et al., 2020; Polero et al., 2021). Under such conditions, the majority of students' youth did not have the opportunity to engage in physical exercises (Berrigan et al., 2020; Halabchi et al., 2020). Thus, violating the main health-improving principle of physical activity - the regularity of aerobic physical activity (Ferreira et al., 2020; Hamaguchi et al., 2020; Esliger \& Tremblay, 2007). A lack of cardiorespiratory fitness is known to negatively affect body mass (percentage of body fat), even in young people involved in sports (Khanna et al., 2020). At this point, a variety of exercise programs and methods were being offered on the Internet through distance technology, which were aimed at replacing the physical activity that students were accustomed to (Hall et al., 2020). Mobile devices have become much more actively used in the practice of physical education of student youth (Lizandra et al., 2020; Osipov et al., 2018). However, a significant number of students who had not previously implemented distance learning in the field of physical education and did not use the Internet fitness industry were unable to reorganize themselves into the process of independent physical education classes (Nyenhuis et al., 2020; Osipov et al., 2020). Moreover, this process required an individual approach to the implementation of physical activity and a longer period to find a suitable and affordable type of training (Berrigan et al., 2020; Makarowski et al., 2020; Thijs et al., 2019). In the context of the pandemic, which is a serious problem for education and physical education in universities (Jumareng et al., 2021), most students were left without help and connection with teachers. In this regard, during this period, there was an acute need for scientifically grounded methodological assistance to students to replace the usual physical exercises with independent physical activity without specialized sports facilities during the spread of COVID-19 in the Russian Federation and around the world.

However, despite the identified relevance of the implementation of physical exercises to increase the optimal functions of the body at all levels to maintain the health of young people, this problem has not been fully disclosed (Halabchi et al., 2020). An unstudied issue, in our opinion, is the methodological preparation of student youth for independent systemic fulfilment of aerobic motor activity. In this regard, the study 
determined the aim of the study - to develop a program for monitoring the walking and running of students according to the "10,000 steps a day" system during the spread of COVID-19 and to prove its effectiveness through improving the body mass index and increasing the level of their physical health.

\section{MATERIAL AND METHODS}

The experimental study was carried out on the basis of the Glazov State Pedagogical Institute and Siberian Federal University. The pedagogical research was carried out for 4 months. The study involved 114 students, regardless of gender. In turn, this sample of participants was divided into two groups: the experimental group (EG) $(n=71)$ and the control group (CG) $(n=43)$. All subjects did not have chronic diseases, however, preliminary analysis revealed that most of the subjects had a low or average level of physical health in terms of levels of functional readiness to perform loads according to diagnostic procedures used for the study. All the participants in the experiment agreed to participate in the experiment and had the experience of independent training with low and average intensity of physical activity of aerobic nature.

To determine the level of general physical health, the methodology of E.A. Pirogova, which allows for an express assessment of the level of physical condition according to the indicator of the circulatory system, according to the formula below: $X=50$ * $\left(\left(700-3{ }^{*} \mathrm{HR}-2.5^{*} \mathrm{BPd}+(\mathrm{BPs}-\mathrm{BPd}) / 3-2.7{ }^{*} \mathrm{~A}+0.28\right.\right.$ * W) / (350$\left.2.7^{*} \mathrm{~A}+0.21{ }^{*} \mathrm{H}\right)$ ), where $\mathrm{HR}$ - heart rate per minute, $\mathrm{H}$ - height, $\mathrm{cm} ; \mathrm{W}$ - body weight; $\mathrm{A}$ - age, full years, BPs - arterial systolic pressure, BPd - arterial diystolic pressure. High level: $X \geq 400$; average level: $400>X$ $>200$; low level: $200 \geq X$.

To analyse the level of physical health in terms of the levels of functional readiness to perform loads and recoverability after the implementation of physical activity, a functional test according to V.S. Anischenko. The test included a set of the following actions and measurements of the heart rate per minute (HR). After a 5-minute rest lying down - HR1. Then calmly rise and stand for 1 minute, measuring HR2. Then 20 full deep squats for 40 seconds. During squats, the arms should vigorously rise forward, and when standing up, they should fall down. After squatting sit down and HR3 for the first minute, then HR4 for the entire second minute and HR5 for the third minute after squatting. As a result, using the following formula, it was necessary to calculate the final result: $X=(H R 2-H R 1) * 10+H R 3+H R 4+H R 5$. High level $X \leq 350$; average level: 350 $<X<420$; low level: $420 \leq X$.

To determine the level of obesity and overweight of students, as one of the key indicators of the physical health of a growing person, the body mass index (BMI) was used, according to the formula: $\mathrm{X}=\mathrm{W} / \mathrm{H}^{2}$, where $\mathrm{W}$ - weight in kilograms and $\mathrm{H}$ - height in meters. High level (optimal weight): $19<\mathrm{BMI}<25$; average level (overweight): $25 \leq \mathrm{BMI} \leq 30$; low level (obesity): $30<\mathrm{BMI}$.

The study used theoretical analysis and generalization of scientific and methodological literature data, a pedagogical experiment, methods of mathematical statistics by Chi-square at $p<.01$ and $p<.05$. Before the beginning of the experiment, the mathematical-statistical non-reliability of the differences for all diagnostics used in the implementation of the experiment between the EG and the CG was recorded at $p>.05$.

\section{RESULTS}

During the experimental period (April - July 2020), students performed daily and weekly self-monitoring of aerobic physical activity, consisting of walking and running. Self-monitoring stimulated the participants of the experiment to self-optimal motor activity for maintaining the physical health of the body according to the 
principle of "10,000 steps a day" in daily, weekly and monthly cycles. During the research period, the athletes from the CG carried out self-monitoring of physical activity using various mobile applications in smartphones and sports gadgets. In turn, the participants in the EG study during the experiment implemented monitoring of individual aerobic activity, consisting of walking and running, using the author's development.

Based on the analysis of special literature on the study of the energy consumption of respondents for physical activity at different speeds and under different conditions (Brown et al. 2003, Eakin et al., 2007; Troiano et al., 2012), an author's program for monitoring students' walking and running was developed according to the system "10,000 steps a day" (Table 1).

Table 1. The program for monitoring aerobic physical activity of students according to the system " 10000 steps a day".

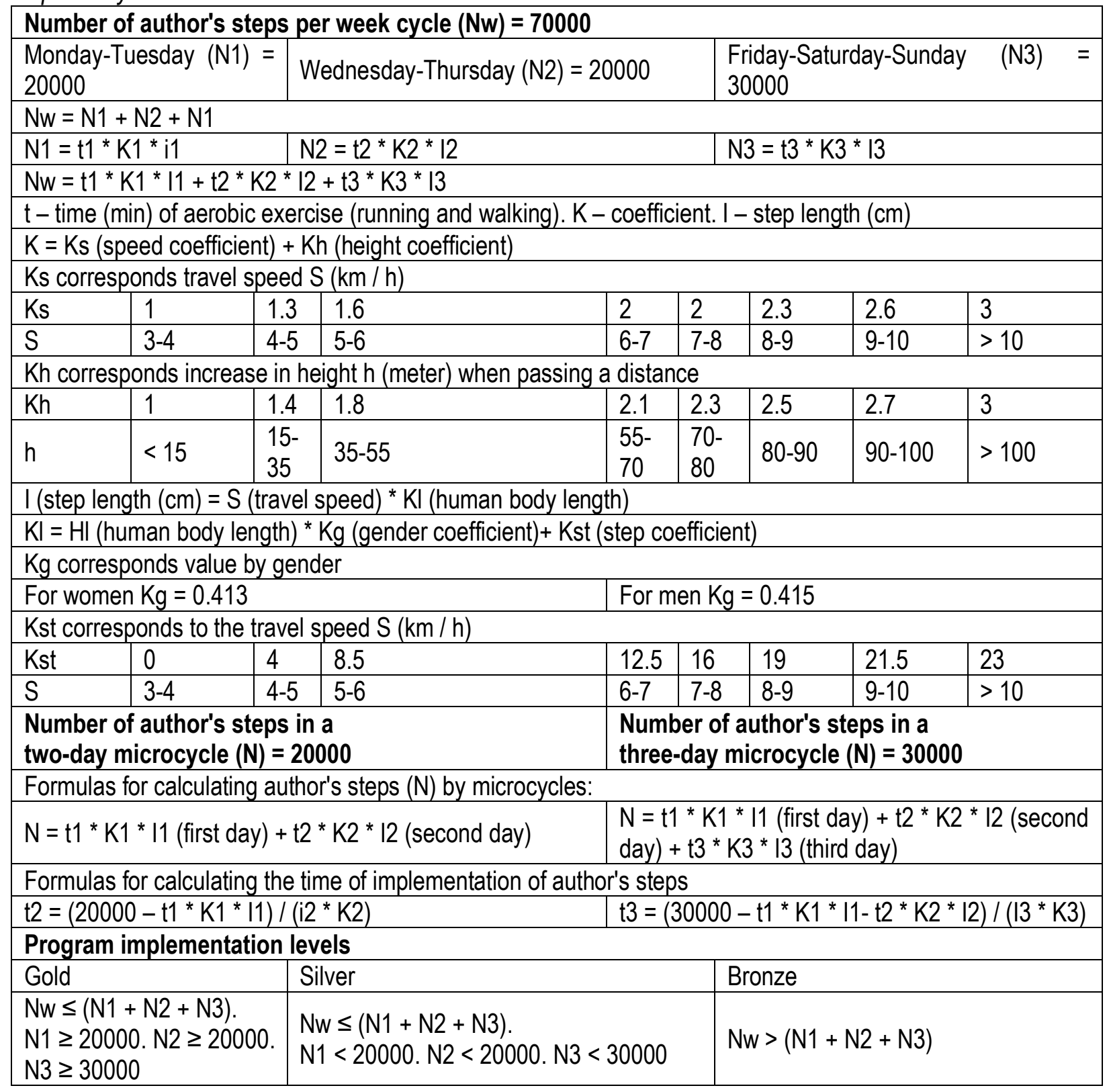


For four months, the participants of the EG study were daily exercising self-control of steps at the moment of performing a cyclic aerobic load. Having counted the steps in the equivalent according to the author's program while walking or running steps at each time interval of cyclic physical activity, the student multiplied the resulting number by the corresponding coefficient. Moreover, when walking or running in an area with a mountainous surface, the result obtained in the previous calculation was multiplied again by a coefficient corresponding to the student's climb during the load. The measurement of the climb during exercise was carried out using a special function "Altitude" in the fitness tracker connected to a smartphone while driving. All data were entered into a special self-control diary on paper or into a mobile phone using a special mobile application. The main goal set for the students from the EG at the beginning of the experiment included a set of author's steps, calculated using the author's system of coefficients, according to the gold level of the author's program implementation.

At the end of the study (July 2020), the students from the EG were divided into three experimental samples to identify more reliable program performance. Differentiation of the EG was realized according to the principle of walking and running, depending on the intensity of the program implementation at the gold, silver or bronze level during the experiment. Students who, during the experiment, gained more gold levels by weekly cycles, in comparison with the aerobic exercise at silver and bronze levels, were enrolled in EG1 ( $\mathrm{n}$ $=24$ ). The study participants of the experimental sample who, at the research stage, scored a greater number of silver levels for weekly cycles, in comparison with the fulfilment of aerobic exercise for gold and bronze levels, were enrolled in EG2 $(n=30)$. The respondents who, during the experiment, gained a greater number of bronze levels by weekly cycles, in comparison with the fulfilment of aerobic exercise at the gold and silver levels, were enrolled in EG3 $(n=17)$. The obtained results of the number of students as a percentage (July 2020 ) in the experimental and control samples for each diagnostic procedure by levels (high, average and low) are presented in Figures 1-3.

As shown in Figure 1, the number of participants in determining the level of general physical health by groups as a percentage of three levels (July 2020) is significantly different between EG1 and CG at a confidence level of $p<.05$ ( $t=8.337)$. In turn, the statistical analysis between EG2 and CG did not reveal a significant difference at $p>.05(t=2.729)$, as well as between $E G 3$ and $C G$ at $p>.05(t=1.807)$.

According to the results of generalizing the data on determining physical health by the levels of functional readiness to perform loads and recovering from physical activity (Figure 2), the number of participants in groups in percentage terms is significantly different between $E G 1$ and $C G$ at a level of reliability $p<.01$ ( $t=$ 44.333 ) and between $E G 2$ and $C G$ at a confidence level of $p<.01(t=14.763)$. In turn, the statistical analysis between EG3 and CG did not reveal the significance of the difference at $p>.05(t=0.894)$.

As shown in Figure 3, the number of students as a percentage by determining the body mass index of students after the implementation of the author's program is significantly different between EG1 and CG at the level of reliability $p<.01(t=40.26)$ and between EG2 and CG at the level of reliability $p<.01(t=23.958)$. Nevertheless, the implementation of the author's program did not show the reliability of the difference between EG3 and CG at $p>.05(t=1.954)$.

The data obtained allow us to identify the following reliably significant results. The effectiveness of the implementation of the author's program for monitoring students' aerobic physical activity according to the "10,000 steps a day" system during the spread of COVID-19 is statistically significant. However, the implementation of the author's model of independent jogging and walking can bring a positive result only if the fulfilment of aerobic physical activity is systematic. Consistency and individual monitoring by students of 
their independent motor activity with the help of the author's recommendations allows increasing the level of physical health both in terms of general characteristics and in the direction of functional readiness to fulfil loads and recoverability after its implementation. The implementation of walking and running according to the program presented in the study during the period of the spread of COVID-19 contributed to the reduction of obesity in students and the prevention of their overweight.

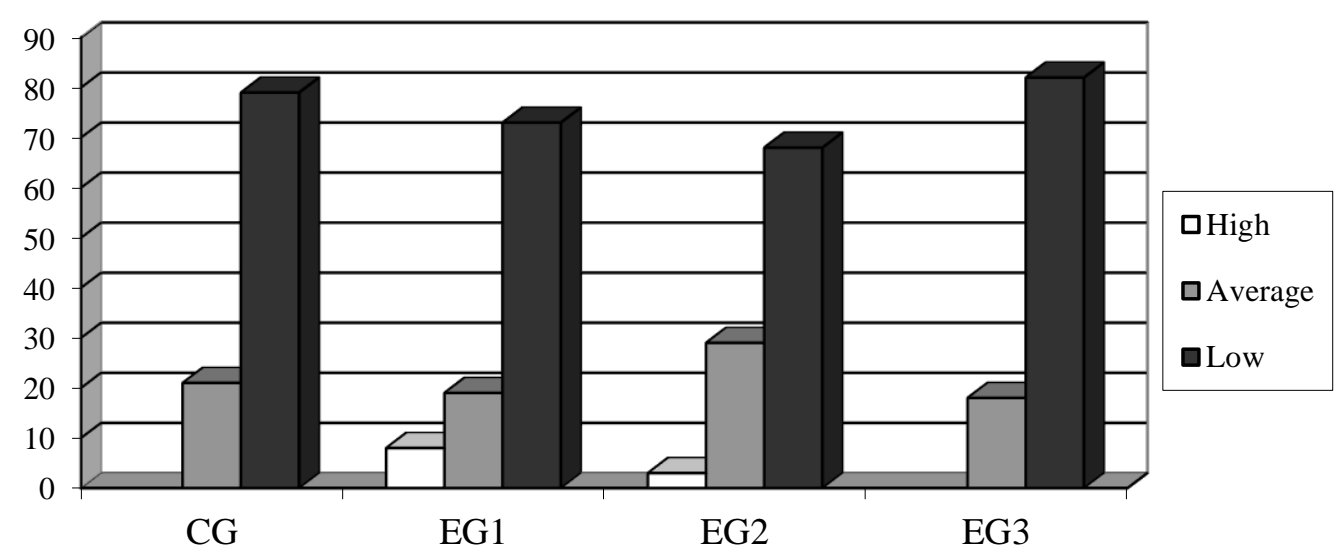

Figure 1. Results of the study to determine the level of general physical health among students of different groups.

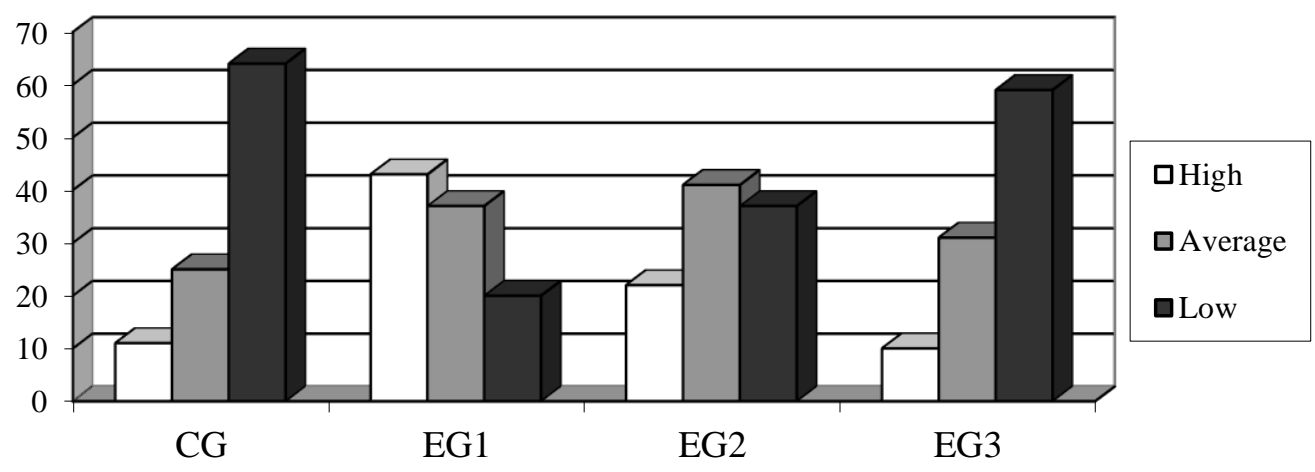

Figure 2. The results of the study on the definition of physical health by the levels of functional readiness to perform loads and recoverability after the implementation of physical activity among students of different groups.

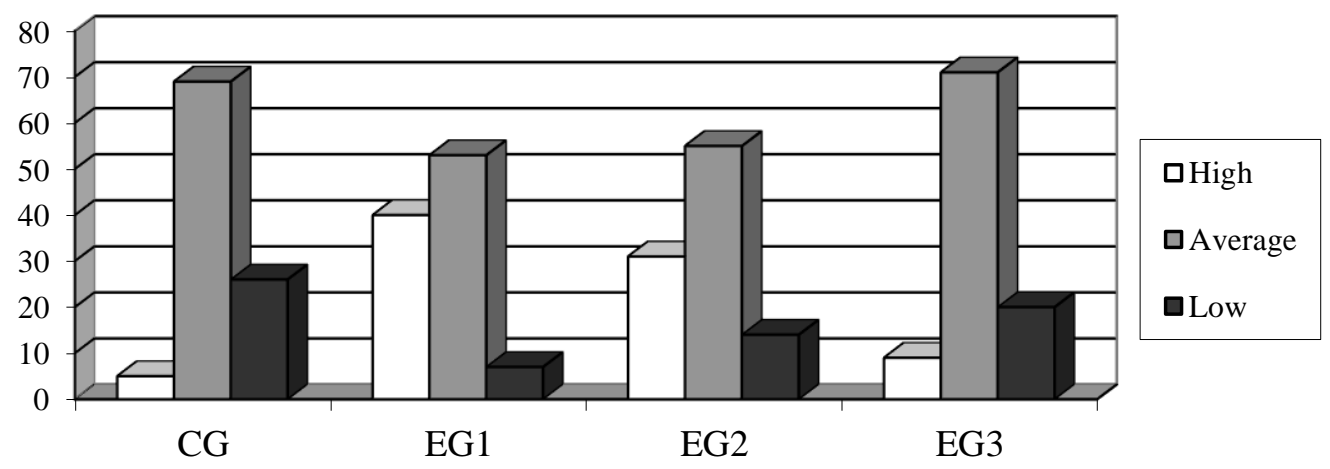

Figure 3. Results of a study on determining body mass index in students of various groups. 


\section{DISCUSSION}

The experimentally proven results of this study are consistent with the conclusions of other studies of the implementation of motor activity in young people of different ages using various self-monitoring programs (Esliger \& Tremblay, 2007, Plotnikoff \& Karunamuni, 2011). Analysis of studies on the dependence of the increase in physical health indicators of student youth (Hildebrand et al., 2014, Thijs et al., 2019) on the systematic nature of their aerobic motor activity during the spread of COVID-19 proves the reliability and relevance of the results obtained in the study (Pitanga et al., al., 2020; Raiola et al., 2020). It is the systematic daily monitoring of aerobic activity that has a positive effect on the functional and health-preserving development of the body (Polero et al., 2021). The need for high-quality monitoring of physical activity of students is emphasized by specialists, since there is a significant risk of error in assessing the volume of physical activity of student youth (Cholewa et al., 2020; Osipov et al., 2020).

The need for a significant increase in the level of daily physical activity of the population is a necessary condition for maintaining health and preventing various diseases (Nagovitsyn et al., 2020). Scientific works empirically prove the effectiveness of increasing the daily number of steps taken by respondents to improve various functional systems of the body and, in general, the physical health of students (Exel et al., 2019; Wennman et al., 2019). The positive effects of the optimal motor regime, independently controlled during the implementation of mobile technologies during the spread of COVID-19, on the psychological characteristics of students are substantiated (Berrigan et al., 2020; Nyenhuis et al., 2020). This ultimately leads to an increase in the mass participation in physical exercises and an increase in the level of physical development of student youth, even during the period of self-isolation (Chen et al., 2020; Ferreira et al., 2020). However, a mobile device in itself is not a factor that motivates a person to change their activities (Hamaguchi et al., 2020; Toth et al., 2018), but acts only as a means of controlling the process of achieving the set goals (Wennman et al., 2019 ). In turn, the results of the presented experiment supplement the previous scientific developments with the proposed author's program. The practical significance of the study is determined by the obtained experimental data, confirmed by mathematical and statistical processing. Namely, that systematic walking and jogging with an optimal motor weekly regimen for a reliably significant healthimproving effect should be at least 70,000 steps according to the author's model per week, provided that the aerobic load is performed consistently.

\section{CONCLUSIONS}

The statistical data revealed during the implementation of the experiment allow us to conclude that the use of self-monitoring, including the daily counting of steps when walking and running, stimulates students to increase their daily, weekly and monthly motor activity. The obtained research data showed that the impact of motional activity has a significantly greater impact when implementing the principle of systematicity and consistency. The study proved on the basis of mathematical and statistical processing of the results that an active lifestyle at a high and medium motor level, including daily walking and jogging, is possible during the period of COVID-19 spread, when specialized sports facilities are closed, and is reliably effective in increasing the level physical health and functional capabilities of those involved. Nevertheless, physical exercises that are not performed systematically and at an optimal motor level are useless for young people in the health aspect. 


\section{REFERENCES}

Aksović, N., Bjelica, B., Joksimović, M., Skrypchenko, I., Filipović, S., Milanović, F., Pavlović, B., Ćorluka, B., \& Pržulj, R. (2020). Effects of aerobic physical activity to cardio-respiratory fitness of the elderly population: systematic overview. Pedagogy of Physical Culture and Sports, 24(5), 208-218. https://doi.org/10.15561/26649837.2020.0501

Berrigan, D., Liu, A., Belcher, B.R., Chao, A., Fang, L., Matthews, C.E., Wang, B., Wang, L., Wang, N., Wang, Y., Yang, L., Linet, M.S., \& Potischman, N. (2020). Physical activity, step counts, and grip strength in the Chinese children and families cohort study. International Journal of Environmental Research and Public Health, 17(17), 1-18. https://doi.org/10.3390/ijerph17176202

Brown, W., Eakin, E., Mummery, W.K., \& Trost, S. (2003). 10,000 Steps Rockhampton: establishing a multi-strategy physical activity promotion in a community. Health Promot J Austr, 14(2), 95-100. https://doi.org/10.1071/he03095

Chen, P., Mao, L., Nassis, G.P., Harmer, P., Ainsworth, B.E., \& Li, F. (2020). Coronavirus disease (COVID-19): The need to maintain regular physical activity while taking precautions. Journal of Sport and Health Science, 9(2), 103-104. https://doi.org/10.1016/.j.jshs.2020.02.001

Cholewa, C., Witkowski, M., Wasik, J., \& Góra, T. (2020). Declared and actual students' physical activity. Physical education of students, 24(3), 135-140. https://doi.org/10.15561/20755279.2020.0302

Eakin, E.G., Mummery, K., \& Reeves, M.M. (2007). Correlates of pedometer use: results from a community-based physical activity intervention trial (10,000 Steps Rockhampton). Int J Behav Nutr Phys Act, 4, 31-39. https://doi.org/10.1186/1479-5868-4-31

Esliger, D.W., \& Tremblay, M.S. (2007). Physical activity and inactivity profiling: the next generation. Canadian journal of public health, 98(2), S195-207. https://doi.org/10.1139/H07-107

Exel, J., Mateus, N., Abrantes, C., Leite, N., \& Sampaio, J. (2019). Physical activity and sedentary behavior in amateur sports: master athletes are not free from prolonged sedentary time. Sport Sciences for Health, 15(2), 385-391. https://doi.org/10.1007/s11332-019-00527-3

Ferreira, M.J., Irigoyen, M.C., Consolim-Colombo, F., Saraiva, J.F.K., \& De Angelis, K. (2020). Physically active lifestyle as an approach to confronting COVID-19. Arquivos Brasileiros de Cardiologia, 114(4), 601-602. https://doi.org/10.36660/abc.20200235

Halabchi, F., Ahmadinejad, Z., \& Selk-Ghaffari, M. (2020). COVID-19 epidemic: Exercise or not to exercise; that is the question! Asian Journal of Sports Medicine, 11(1), e102630. https://doi.org/10.5812/asjsm.102630

Hall, G., Laddu, D.R., Phillips, S.A., Lavie, C.J., \& Arena, R. (2020). A tale of two pandemics: How will COVID-19 and global trends in physical inactivity and sedentary behavior affect one another? Progress in Cardiovascular Diseases. https://doi.org/10.1016/j.pcad.2020.04.005

Hamaguchi, T., Tayama, J., Suzuki, M., Nakaya, N., Takizawa, H., Koizumi, K., Amano, Y., Kanazawa, M., \& Fukudo, S. (2020). The effects of locomotor activity on gastrointestinal symptoms of irritable bowel syndrome among younger people: An observational study. PLoS ONE, 15(5), e0234089. https://doi.org/10.1371/journal.pone.0234089

Hildebrand, M., Van Hees, V.T., Hansen, B.H., \& Ekelund, U. (2014). Age group comparability of raw accelerometer output from wrist-and hip-worn monitors. Medicine and Science in Sports and Exercise, 46(9), 1816-1824, https://doi.org/10.1249/MSS.0000000000000289

Jumareng, H., Setiawan, E., Patah, I., Aryani, M., \& Gani, R.A. (2021). Online Learning and Platforms Favored in Physical Education Class during COVID-19 Era: Exploring Student' Perceptions. International Journal of Human Movement and Sports Sciences, 9(1). 11-18. https://doi.org/10.13189/saj.2021.090102 
Juwono, I., \& Szabo, A. (2020). The efficacy of Self Determination Theory-based interventions in increasing students' physical activity: A systematic review. Physical Activity Review, 8(1), 74-86. https://doi.org/10.16926/par.2020.08.09

Khanna, S., Singh, A., Singh, B., \& Khan, F. (2020). Cardiorespiratory fitness in university level volleyball players and its correlation with body fat. Polish Journal of Sport and Tourism, 27(3). 15-19. https://doi.org/10.2478/pjst-2020-0015

Kuzmina, O., Lebedinskiy V., \& Shvachun, O. (2020). Modern technologies of pedagogical impact and new types of motor activity in student health protection. Teoriya i Praktika Fizicheskoy Kultury, 1, 1416.

Lee, I.M., \& Shiroma, E.J. (2014). Using accelerometers to measure physical activity in large-scale epidemiological studies: Issues and challenges. British Journal of Sports Medicine, 48(3), 197-201. https://doi.org/10.1136/bjsports-2013-093154

Lizandra, J., Valverde-Esteve, T., \& Garcia-Masso, X. (2020). Use of mobile devices as a facilitator of the practice of physical activity in physical education lessons: experience in higher education. Journal of Physical Education and Sport, 20(6), 3629-3634. https://doi.org/10.7752/jpes.2020.06489

Loginov, S. (2019). Daily physical activity and sedentary (inactive) behaviour of adults from Surgut. Human. Sport. Medicine, 19(4), 70-77. https://doi.org/10.14529/hsm190409

Makarowski R, Piotrowski A, Predoiu R, Görner, K., Predoiu, A., Mitrache, G., Malinauskas, R., Bochaver, K., Dovzhik, L., Cherepov, E., Vazne, Z., Vicente-Salar, N., Hamzah, I., Miklósi, M., Kovács, K., \& Nikkhah-Farkhani, Z. (2020). Stress and coping during the COVID-19 pandemic among martial arts athletes - a cross-cultural study. Archives of Budo, 16, 161-171.

Nagovitsyn, R.S. (2014). Conceptual framework of formation of personal physical culture of student based on mobile learning. Teoriya i Praktika Fizicheskoy Kultury, 10, 11-14.

Nagovitsyn R., Osipov A., Kudryavtsev M., Antamoshkin O., \& Glinchikova L. (2020). The Increase of Physical Activity in Persons Using Sports Grounds for Physical Training. Human. Sport. Medicine, 20(1), 100-105. https://doi.org/10.14529/hsm200112

Nagovitsyn, R.S., Tutolmin, A.V., Maksimov, Y.G., Dimova, I.A., Karoyan, A.A., Skryabina, D.Y., \& Volkov, S.A. (2019). Motivation for physical activity of people of different ages. Gazzetta Medica Italiana - Archivio per le Scienze Mediche, 178(10), 799-806. https://doi.org/10.23736/S03933660.18.03965-7

Nagovitsyn, R.S., Zekrin, F.H., Fendel', T.V., \& Zubkov, D.A. (2019). Sports selection in martial arts based on the harmonic stability of results at competitions. Journal of Human Sport and Exercise, 14(4proc), S867-S876. https://doi.org/10.14198//hse.2019.14.Proc4.49

Nyenhuis, S.M., Greiwe, J., Zeiger, J.S., Nanda, A., \& Cooke, A. (2020). Exercise and Fitness in the Age of Social Distancing During the COVID-19 Pandemic. Journal of Allergy and Clinical Immunology: In Practice, 8(7), 2152-2155. https://doi.org/10.1016/j.jaip.2020.04.039

Osipov, A., Kudryavtsev, M., Galimova, A., Plotnikova, I., \& Skurikhina, N. (2020). How can distance learning be used in the physical education of students? Rev Românească Pentru Educ Multidimens, 12(2Sup1), 77-85. https://doi.org/10.18662/rrem/12.2Sup1/292

Osipov, A., Kudryavtsev, M., Kopylov, Y., Kuzmin, V., Panov, E., \& Kramida, I. (2018). The possibility of a significant increase in the level of motor activity in students with the use of the potential of computer technology. Physical education of students, 22(5), 265-271. https://doi.org/10.15561/20755279.2018.0506

Osipov, A., Potop, V., Nagovitsyn, R., Zemba, E., Knyazev, A., Orlova, I., Ratmanskaya, T., \& lermakov, S. (2020). Indicators of physical activity and fitness of male students at Russian universities. Physical education of students, 24(1), 40-46. https://doi.org/10.15561/20755279.2020.0105 
Otaraly, S., Alikey, A., Sabyrbek, Z., Zhumanova, A., Martynenko, I., \& Poteliuniene S. (2020). Evaluation of Kazakhstan Students' Views on Health, Lifestyle, and Physical Activity. Sport Mont, 18(2), 67-72. https://doi.org/10.26773/smi.200607

Pitanga, F.J.G., Beck, C.C., \& Pitanga, C.P.S. (2020). Physical activity and reducing sedentary behavior during the coronavirus pandemic. Arquivos Brasileiros de Cardiologia, 114(6), 1058-1060. https://doi.org/10.36660/abc.20200238

Plotnikoff, R.C., \& Karunamuni, N. (2011). Steps towards permanently increasing physical activity in the population. Curr Opin Psychiatry, 24(2), 162-167. https://doi.org/10.1097/YC0.0b013e3283438107

Podrigalo, L., Artemieva, H., Rovnaya, O., Misevra, N., Sotnikova-Meleshkina, Z., Podavalenko, A., Sokol, K., \& Robak, l. (2019). Features of physical development and somatotype of girls and women involved in fitness. Pedagogics, psychology, medical-biological problems of physical training and sports, 23(4), 189-195. https://doi.org/10.15561/18189172.2019.0405

Polero, P., Rebollo-Seco, C., Adsuar, J.C., Pérez-Gómez, J., Rojo-Ramos, J., Manzano-Redondo, F., Garcia-Gordillo, M.Á., \& Carlos-Vivas, J. (2021). Physical activity recommendations during COVID19: Narrative review. International Journal of Environmental Research and Public Health, 18(1), 124. https://doi.org/10.3390/ijerph18010065

Raiola, G., Aliberti, S., Esposito, G., Altavilla, G., D'Isanto, T., \& D'Elia, F. (2020). How has the Practice of Physical Activity Changed During the COVID-19 Quarantine? A Preliminary Survey. Teoriâ Ta Metodika Fìzičnogo Vihovannâ, 20(4). 242-247. https://doi.org/10.17309/tmfv.2020.4.07

Saatchian, V., \& Azimkhani, A. (2020). An Analysis of the Role of the Social Acceptance of University Students' Bicycle Use in Sustainable Urban Development when Epidemics Spread. Sport Mont, 18(3), 7-11. https://doi.org/10.26773/smi.201013

Thijs I., Fresiello L., Oosterlinck W., Sinnaeve P., \& Rega F. (2019). Assessment of Physical Activity by Wearable Technology During Rehabilitation After Cardiac Surgery: Explorative Prospective Monocentric Observational Cohort Study. JMIR Mhealth Uhealth, 7(1), e9865. https://doi.org/10.2196/mhealth.9865

Toth L., Park S., Pittman W., Sarisaltik D., Hibbing P., Morton A., Springer C., Crouter S., \& Bassett D. (2018). Validity of Activity Tracker Step Counts during Walking, Running, and Activities of Daily Living. Translational Journal of the ACSM, 3(7), 52-59.

Troiano RP, Pettee G, Welk GJ, Owen N, \& Sternfeld B. (2012). Reported physical activity and sedentary behavior: why do you ask? Journal of physical activity \& health, 9(1), 68-75. https://doi.org/10.1123/jpah.9.s1.s68

Wennman, H., Pietilä, A., Rissanen, H.,Valkeinen, H., Partonen, T., Mäki-Opas, T., \& Borodulin, K. (2019). Gender, age and socioeconomic variation in 24-hour physical activity by wrist-worn accelerometers: the FinHealth 2017 Survey. Scientific Reports, 9(1), 6534. https://doi.org/10.1038/s41598-019-43007-x

\section{(9) $(\Theta \Theta \Theta$}

This work is licensed under a Attribution-NonCommercial-NoDerivatives 4.0 International (CC BY-NC-ND 4.0). 